Western University Scholarship@Western

1978

\title{
Activist Monetary Policy under Rational Expectations
}

Peter Howitt

Follow this and additional works at: https://ir.lib.uwo.ca/economicsresrpt

Part of the Economics Commons

Citation of this paper:

Howitt, Peter. "Activist Monetary Policy under Rational Expectations." Department of Economics Research Reports, 7816. London, ON: Department of Economics, University of Western Ontario (1978). 
RESEARCH REPORT 7816

ACTIVIST MONETARY POLICY UNDER

RATIONAL EXPECTATIONS

by

Peter Howitt

Apri1, 1978

Depariacti of Fongaiics Library
NOV 21983
Dniyersity of Wyestern Ontario


Activist Monetary Policy Under

Rational Expectations

by

Peter Howitt
Department of Economics
University of Western Ontario

An earlier version of this paper was presented at the meetings of the American Economic Association, New York, December 1977. I am indebted to Herschel Grossman for pointing out a serious problem with this earlier version, to Russell Boyer, Joel Fried, Robbie Jones, David Laidler, and Michael Parkin for helpful comments, and to the Canada Council for financial support. 
Activist Monetary Policy Under Rational Expectations

by Peter Howitt

The purpose of this paper is to argue that the pursuit of an activist monetary policy may make economic sense even when people's expectations are formed rationally. The paper presents a simple model in which (1) prices are costly to adjust, (2) there is uncertainty concerning the parameters affecting aggregate demand, and (3) there are positive costs of gathering and processing information. By reference to this model it can be shown that an activist monetary policy may or may not be useful in offsetting aggregate disturbances, depending upon the extent of information costs and of parameter uncertainty.

\section{INTRODUCTION}

By an activist monetary policy I mean a policy whereby the monetary authority permits the money supply to react systematically to information concerning aggregate disturbances. The proposition commonly known as the Sargent-Wallace (hereafter SW) proposition ${ }^{1}$ asserts that an activist monetary policy cannot succeed in offsetting aggregate disturbances when people's expectations are formed rationally unless the monetary authority possesses information unavailable to private agents. It asserts that in the absence of such superior information systematic variations in the money supply will be anticipated and thus neutralized even in the short run.

The SW proposition has been criticized by previous writers. Taylor (1975) pointed out that it will take private agents time before they learn 
the exact nature of the monetary policy. ${ }^{2}$ During this transition period the SW proposition is invalid. Poole (1976), Fischer (1977), and Phelps and Taylor (1977) have pointed out that even if private agents possess the same information as the monetary authority they may not be able to act upon it immediately because of contractual precommitments, in which case the SW proposition is invalid. It has also been widely acknowledged that if the arguments underlying the SW proposition were valid it would be difficult to explain the observed persistence of movements in output and employment. 3

The present paper focuses upon another objection to the SW proposition: namely that it fails to take into account (1) the costs of gathering and processing information, and (2) uncertainty concerning the structure of the economic system. People may choose not to collect and process the monetary authority's information concerning aggregate disturbances when it is costly to do so. ${ }^{4}$ Indeed, everyday observation suggests that most people pay no attention to such information. In such circumstances people may still be forming their expectations rationally, in the sense that they are making efficient use of (costly) information, yet they are not in a position to anticipate and neutralize the effects of an activist monetary policy. In order for the SW proposition to be true the monetary authority's information must not only be available to private agents it must also be economically useable by private agents.

This qualification to the SW proposition has been noted by Barro (1976) who argued nevertheless that the monetary authority could do just as well by disseminating its information as it could by varying the money supply. However, this paper attempts to show that such a disseminating policy may be inferior to an activist policy when there is uncertainty concerning the values of parameters in the economic system, because (1) people may not have enough 
incentive to process information and (2) even if people do process the information there is no guarantee that this will produce the same outcome as would a properly designed monetary policy. A demonstration of this argument can be made precise only in terms of a formal model, but it can be sketched in the following terms.

First, even if the information concerning aggregate disturbances is provided to people, they must still incur the cost of processing the information if they are to use it. But they may not find it economical to incur that cost if they think that not many other people will be using the information, even when the social value of the information exceeds the processing cost. Consider, for example, an agent who is deciding what price to charge for the single good that he sells. Suppose he is told that the demand for money has doubled. If he thinks that all other agents are using this information he can calculate that his best course of action will be to cut his price in half, along with everyone else. The information may be quite valuable to him and to society because failure to conform in reducing his price would leave him charging a suboptimal relative price. But if he thinks that no other agent is using the information his best course of action will depend upon the effects of that change in the demand for money upon the demand for his product. If this effect is difficult to estimate accurately then the information may have , little value to him. In order for the private value of such information to equal its social value it may be necessary for a convention like "universal indexing" to exist that leads people to believe that everyone else will be using the information as we11. Everyday observation again suggests that such a convention rarely exists.

Second, in a world without complete Arrow-Debreu contingent claim markets there is no guarantee that even an otherwise frictionless competitive 
equilibrium will be efficient with respect to the information possessed by private agents. It is possible that the monetary authority is in a position to make better use of aggregate information than are private agents, even when the above-mentioned indexing convention exists. In the example of the previous paragraph, Brainard's (1967) analysis suggests that if the values of the parameters of the economic system are not known with certainty then the optimal reaction of the monetary authority is to allow the money supply to increase, but by less than 100 percent. But if the information is disseminated prices may indeed fall in half, which would be equivalent to a 100 percent increase in the money supply. As in the theory of the second best, full information results in the best equilibrium but when information is incomplete then more information does not necessarily result in a better equilibrium. 5

The remainder of the paper attempts to make these arguments more precise by developing a simple model of a monetary economy in which prices are costly to adjust. Section 2 describes the basic features of the model; section 3 analyzes the private decision whether or not to use information; section 4 characterizes the optimal policy of the monetary authority showing how an activist policy may be justified by the first of the above arguments; section 5 considers a variant of the model in which the second of the above arguments may be used to justify an activist policy; and section 6 contains some concluding remarks.

\section{THE BASIC MODEL}

Preliminaries

Consider an economy with a number of essentially identical individual agents. There are only two tradeable objects in the economy: a good and money. Each agent is capable of producing the good but derives utility from consuming only units of the good that are produced by other agents. Trading is organized 
as follows. At the beginning of each period each agent must post a price at which he stands willing to sell whatever amounts are demanded from him by others. After all prices are posted each agent then learns the values of certain parameters and variables that allow him to calculate his sales for the period. Each agent then chooses his demands for the good and proceeds to execute these demands by visiting other agents and offering money for the good. Meanwhile each agent must produce to meet the orders placed with him by others. It is assumed to be prohibitively costly for any agent to change his price during the period.

\section{Demand Functions}

Let $\mathrm{m}$ be the real quantity of money possessed by an agent before formulating his demands, and let $q$ be his sales (in units of the good) for the period. Suppose that all other agents are posting a uniform price and let $r$ be his relative price. The agent's utility function is assumed to depend upon his demand for the good, $\hat{q}$, his demand for real balances, $\hat{\mathrm{m}}$, and his production, $q$, according to the particular function:

$$
U=K \hat{q}^{a}(\hat{m}+x)^{1-a}-(k / 2) q^{2}
$$

where $0<a<1, k>0, K=a^{-a}(1-a)^{a-1}$, and $x$ is a shift parameter which we may call the level of aggregate demand. This particular utility function has been chosen simply for analytical convenience. After he has posted his price and learned the values of $q, m, a$, and $x$, the agent forms his demands by maximizing $U$ subject to the budget constraint:

$$
\hat{\mathbf{m}}+\hat{q}=\mathbf{m}+\mathrm{rq} \text {, }
$$

resulting in the demand function:

$$
\hat{q}=a(m+r q+x)
$$

and in the indirect utility function:

$$
\mathrm{v}(\mathrm{m}, \mathrm{q}, \mathrm{x}, \mathrm{r})=\mathrm{m}+\mathrm{rq}+\mathrm{x}-(\mathrm{k} / 2) \mathrm{q}^{2} \text {. }
$$


But all agents are essentially identical; that is, the values of $x$, $\mathrm{m}$ and $\mathrm{a}$ are the same for all agents, and, as we shall see, each agent will be led to post the same price $(r=1)$. We may assume that when all prices are the same each agent shares the same sales; thus the actual quantity demanded must satisfy (3) and the "Fix-price equilibrium" condition: $q=\hat{q}$ 。 This equilibrium quantity is:

$$
q=b(m+x) ; b=a /(1-a) \in(0, \infty)
$$

Equation (5) describes effective demand as a function of the supply of money, the level of aggregate demand, and the reduced-form "multiplier" coefficient b.

\section{The Money Supply}

Let $M$ denote the supply of nominal balances per capita. Let $s$ denote the "indicator" used by the monetary authority. The money supply is assumed to be determined by the simple reaction function:

$$
M=\bar{M}(1-g s)
$$

where $\bar{M}(>0)$ may be interpreted as the "average" money supply, and $g(>0)$ is the monetary authority's reaction coefficient.

The rule (6) is rationalized by supposing that there is a connection between the indicator $s$ and the level of aggregate demand $x$; namely that:

$$
\mathbf{x}=c s
$$

where $c$ is a random variable whose exact value cannot be determined by the monetary authority when the money supply is fixed for the period.

Let $\mathrm{P}$ denote the price posted by all sellers. Then the real money supply per person is defined as:

$$
\mathrm{m}=\mathrm{M} / \mathrm{P}
$$




\section{The Price-Setting Decision}

Equation (5) describes the demand per person for the good when all posted prices are identical. To make sense of the price-setting decision we must specify the demand function facing a seller when he is free to post a price different from $P$. Absolute consistency with the preceding discussion would require us to postulate an infinitely elastic demand function, because the products of the different sellers are assumed to be homogeneous. But this would create extraneous problems that can be avoided by assuming the goods to be "almost" perfectly homogeneous. Suppose that the demand function facing each seller is:

$$
q=\operatorname{Max}\{b(m+x)+n(1-r), 0\}
$$

where $\mathrm{n}$ is a large, positive number. (In the case of perfect homogeneity the demand function would be the limit of (9) as $n \rightarrow \infty_{0}$ )

At the time that prices are posted the sellers are uncertain of the exact values of the parameters $b$ and $c$, and they may or may not know the exact value of the indicator, s. Suppose that b, $c$, and $s$ are independent random variables satisfying:

$$
\begin{aligned}
& E(b)=\beta>0 ; \quad E(c)=\gamma>0 ; E(s)=0 \\
& \operatorname{var}(b)=\sigma_{b}^{2} ; \quad \operatorname{var} c=\sigma_{c}^{2} ; \quad \operatorname{var}(s)=\sigma_{s}^{2}
\end{aligned}
$$

Let I denote the information set of the price-setter; that is, I is a subset of the random variables $\{b, c, s\}$, the exact values of which condition his expectations. In particular we shall consider only the two cases: (1) $I=\{s\}$, in which case we may say that the seller monitors the monetary authority's indicator, and (2) $I=\phi,{ }^{6}$ in which case the agent chooses not to monitor the indicator. In the present section we may take $I$ as given. The next section analyzes the agent's decision as to what to include in $I$. The assumption of 
rational expectations is that the agents all form psychological expectations that are equal to the mathematical expectations implied by this model, conditional upon $I$.

Thus the price-setter's decision problem is to choose $r$ so as to maximize the expected value of his indirect utility function (4), conditional upon I, subject to (6) (9). Assume that a price is chosen so that $q>0$ with probability 1 , and define $\bar{q}_{n} \equiv \mathrm{n} /(1+\mathrm{nk})$. Then the first-order conditions of the price-setter's problem imply that:

$$
E[b(\bar{M}(1-g s) / P+c s)+n(1-r) \mid I]=r \bar{q}_{n}
$$

The solution to (11) can be written as the relative-price function:

$$
r=r_{n}(P, \bar{M}, g, I)
$$

In the limiting case where $\mathrm{n} \rightarrow \infty$, (11) states that the seller's expectation of demand should equal $\mathrm{rk}^{-1}$, which is simply the usual perfectly-competitive supply function. Thus (12) may be interpreted as stating that each seller will post a relative price such that expected excess demand is zero。

\section{Equilibrium Prices, Quantities, and Utilities}

Since all agents are essentially identical we may assume that they will all choose to use the same information set and that they will all be motivated to post the same prices. Thus the actual value of $P$ will be determined by the condition that the value of $r$ in (12) be equal to unity. In other words, each seller will expect the market price to take on a value such that everyone is induced to conform with that price (no other expectation could be rational according to our definition) and this will obviously be a selffulfilling expectation. Let the superscript $i$ denote the information set; $i=1$ denoting $I=\{s\}$ and $i=2$ denoting $I=\phi$. Then the market price can be expressed as: 
(13)

$$
\mathrm{P}=\mathrm{P}_{\mathrm{n}}^{\mathrm{i}}(\overline{\mathrm{M}}, \mathrm{g}) \quad \mathrm{i}=1,2
$$

and,from (11), it must satisfy the condition:

$$
E[b(\bar{M}(1-g s) / P+c s) \mid I]=\bar{q}_{n}
$$

In the limiting case of perfect homogeneity (14) simply states that the market price will be set so that the expected market demand equals the competitive market supply。 In other words, there is expected market-clearing. ${ }^{7}$ Let $\bar{m}_{n} \equiv \bar{q}_{n} / \beta$. From (10), (13) and (14), the prices can be expressed as :

$$
\begin{aligned}
& P_{n}^{1}(\bar{M}, g)=\bar{M}(1-g s) /\left(\bar{m}_{n}-\gamma s\right) \\
& P_{n}^{2}(\bar{M}, g)=\bar{M} / \bar{m}_{n}
\end{aligned}
$$

Thus the equilibrium quantity of output can be expressed as a function of the information set, the reaction coefficient $g$, and the random variables $b, c$ and $s$ :

$$
\begin{aligned}
& q_{n}^{1}=b\left(\bar{m}_{n}+(c-\gamma) s\right) \\
& q_{n}^{2}=b\left(\bar{m}_{n}(1-g s)+c s\right)
\end{aligned}
$$

The essence of the SW proposition is contained in (17). If agents monitor $s$ then the behaviour of the quantity $q$ is independent of the reaction coefficient g. On the other hand, (18) shows that $q$ is affected by $g$ if no monitoring occurs。

From (10), (17), and (18), the mean and variance of output per person can be expressed as:

$$
\begin{aligned}
& E\left(q_{n}^{1}\right)=E\left(q_{n}^{1} \mid s\right)=E\left(q_{n}^{2}\right)=\bar{q}_{n} \\
& \operatorname{var} q_{n}^{1}=\sigma_{b}^{2} \ddot{m}_{n}^{2}+\sigma_{s}^{2}\left(\beta^{2}+\sigma_{b}^{2}\right) \sigma_{c}^{2}
\end{aligned}
$$


(21)

$$
\operatorname{var} q_{n}^{2}=\sigma_{b}^{2} \bar{m}_{n}^{2}+\sigma_{s}^{2}\left(\beta^{2}+\sigma_{b}^{2}\right)\left[\sigma_{c}^{2}+\left(\gamma-g \bar{m}_{n}\right)^{2}\right]
$$

From (4) and (15) (19), the expected utility of each agent may be expressed as :

$$
v_{n}^{i}(g)=E V\left[M / P_{n}^{i}, q_{n}^{i}, x, 1\right]=\bar{m}_{n}+\bar{q}_{n}-(k / 2) q_{n}^{-2}-(k / 2) \operatorname{var} q_{n}^{i} ; i=1,2 .
$$

It follows from $(20) \sim(22)$ that the gain to society from everyone monitoring the indicator arises solely from the consequent reduction in the variability of output. This reduction in variance yields a welfare gain because the marginal utility of more production is (by assumption) a constant but the marginal cost is increasing, so that total utility is a convex function of the level of output.

3. THE MONITORING DECISION Equations $(15) \sim(22)$ show how the market price, output, and expected utility depended upon the information set and the reaction coefficient. This section analyzes the choice of the information set.

Let $z_{m}(>0)$ denote the cost, in utils, of monitoring the indicator. For future reference assume that $z_{m}=z_{c}+z_{p}$ where $z_{c}$ is the cost of collecting the information (i.e., of determining the exact value of $s$ ) and $z_{p}$ is the cost of processing the information (i.e., of computing and posting the optimal price given the value of $s$ ). Each agent will choose to monitor if the gain to him in expected utility is at least as great as $z_{\mathrm{m}^{\circ}}$

The size of this gain will clearly depend upon whether or not the other agents are monitoring. Consider first the case in which none of the other agents is monitoring. In this case the agent will derive the expected utility $v_{n}^{2}(g)$, as determined by (22), if he too chooses not to monitor. But if he chooses to monitor, the market price will continue to be $\mathrm{P}_{\mathrm{n}}^{2}$, as in (16), and the agent can now profit from knowing the exact value of the indicator 
before setting his own price. From (11) and (16) it follows that the monitoring firm's relative price will be:

$$
r_{n}\left(P_{n}^{2}, \bar{M}, g, s\right)=1+s \beta\left(\gamma-g \bar{m}_{n}\right) /\left(\bar{q}_{n}+n\right)
$$

Let $v_{n}^{3}(g)$ denote the expected utility of the agent who monitors when no one else is monitoring. Then, from (4), (7) (10), (16), and (21) (23), the gain in expected utility from deciding to monitor when others are not monitoring is :

$$
v_{n}^{3}(g)-v_{n}^{2}(g)=\varphi(n) \sigma_{s}^{2} \beta^{2}\left(\gamma-g \bar{m}_{n}\right)^{2},
$$

where $\varphi(n)=(1+n k)^{2} / 2 n(2+n k)$. Note that:

$$
\varphi(n)>(k / 2) \text {, and } \varphi(n) \rightarrow(k / 2) \text { as } n \rightarrow \infty \text {. }
$$

The nature of this gain is easy to see. The expected output of the agent is not affected by the decision to monitor but its variance is, and, as we have argued, a reduction in variance increases expected utility. Specifically, whenever the level of aggregate demand is high $(s>0)$ the monitoring agent will, according to (23), raise his price, thereby damping the increase in his sales. Likewise when $s<0$ the monitoring agent will bolster his sales by reducing $r$. Not only does this reduce variability it also adds to the agent's expected revenue. In the limiting case of perfect homogeneity, (23) implies that these changes in $r$ will be imperceptible. In this case the agent is able to adjust the mean position of his random sales schedule whenever a non-zero value of $s$ is observed so that the expected value of his sales conditional upon $s$ is equal to $\vec{q}^{-8}$ and the entire gain to the agent from deciding to monitor arises from the resulting reduction in the variance of sales. In particular, (24) implies that the gain is equal to $(k / 2)$ times this reduction in variance. Next, consider the case in which all of the other firms are monitoring. In this case the agent will derive the expected utility $v_{n}^{1}(g)$ as determined by (22) if he too chooses to monitor. But if he chooses not to monitor then the 
price will continue to be $\mathrm{P}_{\mathrm{n}}^{1}$ as in (15), and the agent will lose by not being able to foresee before setting his own price the variations in $s$ and in $\mathrm{P}_{\mathrm{n}}^{1}$ that his competitors are taking into account. The non-monitoring agent will choose a price $\hat{\mathrm{P}}$ so as to maximize

$$
\operatorname{EV}\left[M / P_{n}^{1}, q_{n}^{1}+n\left(1-\hat{P} / P_{n}^{1}\right), x, \hat{P} / P_{n}^{1}\right]
$$

Let $v_{n}^{4}(g)$ denote the expected utility of the agent who doesn't monitor when others are monitoring. Then, as the appendix demonstrates, the gain in expected utility from deciding to monitor when others are monitoring is:

$$
v_{n}^{1}(g)-v_{n}^{4}(g)=\Psi(n) \frac{\operatorname{var} e_{n}}{1+\operatorname{var} e_{n}}
$$

where $e_{n}=P_{n}^{1}(\bar{M} ; g, s)^{-1}\left[E P_{n}^{1}(\bar{M} ; g, s)^{-1}\right]^{-1}$ is the reciprocal of the market price, expressed as a ratio to its mean value, and where $\Psi(n)=n+n^{2} k / 2$ 。 Note that:

$$
: \Psi(n) \rightarrow \infty \text { as } n \rightarrow \infty \text {. }
$$

If everyone is to monitor then the gain from deciding to monitor when everyone else is monitoring must be at least as great as the monitoring cost; i.e.,

$$
v_{n}^{1}(g)-v_{n}^{4}(g) \geqq z_{m}
$$

Likewise, if no one is to monitor it is necessary that

$$
v_{n}^{3}(g)-v_{n}^{2}(g) \leqq z_{m}
$$

From (24) and (26) it follows that for large enough $n$ at least one of these conditions must be satisfied. But it also follows that both of them may be satisfied. In other words, convention appears to play an important role in the monitoring decision. It may be that everyone will monitor if they all expect everyone else to but no one will monitor if they all expect no one else to. I shall assume that monitoring will occur if and only if (29) is 
violated--in other words that the convention of monitoring will develop only when the convention of non-monitoring is unsustainable. Notice, however, that when the reaction coefficient assumes the value:

$$
\hat{\mathrm{g}}_{\mathrm{n}}=\gamma / \overline{\mathrm{m}}_{\mathrm{n}}
$$

then the convention of monitoring could never be sustained as long as $z_{m}>0$, because, from (15), (24) and (26):

$$
v_{n}^{1}\left(\hat{g}_{n}\right)-v_{n}^{4}\left(\hat{g}_{n}\right)=v_{n}^{3}\left(\hat{g}_{n}\right)-v_{n}^{2}\left(\hat{g}_{n}\right)=0
$$

In order to simplify the analysis further, let us assume the limiting case of perfect homogeneity. Then, from (24), (25) and (29), the necessary and sufficient condition for monitoring to occur is:

$$
(k / 2) \lambda_{c} \sigma_{x}^{2} \beta^{2}(1-g / \hat{g})^{2}>z_{m}
$$

where $\lambda_{c}=\frac{\gamma^{2}}{\gamma^{2}+\sigma_{c}^{2}}$ is a measure of the accuracy of the indicator, being the square of the coefficient of correlation between $x$ and the conditional forecast ys of $x$ based on the indicator, $\sigma_{x}^{2}=\operatorname{var} x$ is the variance in aggregate demand, and $\hat{g}=\gamma / \mathrm{k} \beta$.

According to (32), the likelihood of monitoring occurring is larger:

(1) the larger is the slope, $k$, of the typical producer's marginal cost schedule, because the larger this slope the more the firm loses from variability in its demand that could be avoided by monitoring; (2) the more accurate is the indicator, because an inaccurate indicator conveys little useful information; (3) the more variable is the level of aggregate demand, because there is little gain in monitoring a variable that is relatively constant; (4) the larger is $\beta$, because there is little gain to monitoring a variable if its expected effect on demand is small; and (5) the closer is the reaction coefficient to $\hat{g}$, because when $g=\hat{g}$ then, as can be inferred from comparing (20) to (21), the monetary 
authority is already accomplishing everything that private agents could accomplish by monitoring.

4. OPTIMAL MONETARY POLICY AND THE INCENTIVE TO MONITOR

Three implications of this analysis are worth noting here. First, the SW proposition is valid for all values of $g$ satisfying (32). For in this case monitoring will occur, and, as noted before, the behaviour of output is unaffected by the value of $g$. According to (20) and (22) each agent's expected utility will also be unaffected by the value of $g$.

Second, whatever can be accomplished by monitoring can be accomplished just as well by having the monetary authority set $g=\hat{g}$ 。 According to (32) no monitoring would occur, but according to (17), (18), and (22) the behaviour of output and expected utility would be the same as if monitoring was occurring。

Third, as was argued in the introduction above, private agents may not have much incentive to monitor s even when the social gains from everyone deciding to monitor are large. That is, the private value of monitoring: $v^{3}(g)-v^{2}(g)$ may be small when the social value: $v^{1}(g)-v^{2}(g)$ is large. In particular, it follows from (20) (22) and (24) that:

$$
\left[v^{3}(g)-v^{2}(g)\right]=\lambda_{b}\left[v^{1}(g)-v^{2}(g)\right]
$$

where $\lambda_{b}=\beta^{2} /\left(\beta^{2}+\sigma_{b}^{2}\right)$ is a measure of the predictability of the effect upon effective demand of changes in $x$, being the square of the coefficient of correlation between the actual effect $b x$ and the predicted effect $\beta x_{0}$. If the value of the coefficient $b$ is known with certainty, then the private and social values coincide. In the limiting case of pure uncertainty (when $\beta=0$ ) the private value is zero.

The reason for this divergence of private from social value is seen most easily in the case of a perfectly reliable indicator $\left(\sigma_{c}^{2}=0\right)$. In this case, 
fluctuations in aggregate demand would be completely offset by the monetary authority setting $g=\hat{g}$, which would render the sum $(m+x)$ independent of $x$ (and equal to $\bar{m}$ ). As we have just argued the same effect would be accomplished if everyone were to monitor. Thus the social gain to monitoring is the gain resulting from the elimination of all variance in out put associated with variations in the level of aggregate demand. But when no one else is monitoring the isolated agent who decides to monitor cannot eliminate all of this variability. Whatever he does to his price he cannot alter the fact that the sum $(m+x)$ will change when $x$ changes. The best he can do is to offset by variations in $r$ the predicted effect of $(m+x)$, which may account for only a small fraction of the variance in the actual effect.

A complete characterization of optimal monetary policy goes as follows. Consider three policies. (1) Policy $\mathrm{N}$ is the Neutral policy: $\mathrm{g}=0$, which is assumed to result in no administrative cost. (2) Policy D is the Disseminating policy suggested by Barro of setting $g=0$ but also publicizing the value of $s$, which is assumed to result in the administrative cost $z_{d}$ per person。 (3) Policy A is the Activist policy of setting $g=\hat{g}$, resulting in the administrative cost $z_{a}$. Assume that the cost $z_{a}$ is incurred whenever any non-zero value of $g$ is chosen. Then policies $N, D$, and $A$, are the only possible candidates as optimal policies. Which policy is optimal will depend upon the relationships between the costs and benefits of monitoring and the administrative costs of the different policies. Let

$$
\mathrm{v}^{\mathrm{s}} \equiv \mathrm{v}^{1}(0)-\mathrm{v}^{2}(0)=(\mathrm{k} / 2) \lambda_{\mathrm{c}} \operatorname{var}(\mathrm{bx})
$$

denote the social gain to monitoring and $v^{p} \equiv v^{3}(0)-v^{2}(0)=\lambda_{b} v^{s}$ denote the private gain to monitoring, when $g=0$. Then according to (32) monitoring never occurs under policy $A$, it will not occur under policy $N$ if $\lambda_{b} v^{s} \leqq z_{c}+z_{p}$ and it will not occur under policy $D$ if $\lambda_{b} V^{S} \leqq z_{p^{\circ}}$ Table 1 below depicts the 
$\underline{T a b l e} 1$

Cost per Person of Monetary Policy

\begin{tabular}{|c|c|c|c|}
\hline & N & D & A \\
\hline$z_{c}+z_{p}<\lambda_{b} v^{s}$ & $z_{c}+z_{p}$ & $z_{d}+z_{p}$ & $z_{a}$ \\
\hline $\begin{array}{l}I I \\
z_{p}<\lambda_{b} V^{s} \leqq z_{c}+z_{p}\end{array}$ & $v^{s}$ & $z_{d}+z_{p}$ & $z_{a}$ \\
\hline $\begin{array}{l}\text { III } \\
\lambda_{b} V^{s} \leqq z_{p}\end{array}$ & $v^{s}$ & $z_{d}+v^{s}$ & $z_{a}$ \\
\hline
\end{tabular}

cost per person of the different policies in the three situations indicated, where the cost is measured as $\mathrm{v}^{1}(0)$ minus the expected utility resulting from the policy, plus the monitoring and administrative costs. In each situation the optimal policy is the one with the least cost.

Note that if the indicator is unreliable enough (i.e., $\lambda_{c}$ small enough) or if effective demand is stable enough (var (bx) small enough), ceteris paribus, then a Neutral policy will be optimal because both of these factors make $\mathrm{V}^{\mathrm{s}}$ sma11. Both of these factors also figure prominently in Friedman's (1953, 1968) case against activist policy. For the same reason, a small slope to marginal cost (small k) favours a Neutral policy. Note also that in situation III the Disseminating policy is dominated by the Neutral policy.

For our purposes the most important implication to note about Table 1 is that an Activist policy will be optimal whenever $z_{a} \leqq v^{S} \leqq z_{p} / \lambda_{b}$; that is if (1) the indicator is reliable enough, effective demand is unstable enough, or marginal cost rises fast enough that $\mathrm{V}^{\mathrm{S}}$ exceeds the cost of administering an Activist policy, and (2) the cost of processing the information contained in the indicator is large enough or the predictability of the effect 
of changes in the level of aggregate demand is small enough that $\mathrm{V}^{\mathrm{S}} \leqq \mathrm{z}_{\mathrm{p}} / \lambda_{\mathrm{b}}$. These conditions do not require the monetary authority to possess any cost advantage. They may hold even if the cost of administering an Activist policy is much larger than the private cost of processing information. If the conditions hold then an Activist policy is optimal because despite the large social gain to monitoring no one will do it even if they are saved the cost of collecting information. For even under a Disseminating policy the user of the information contained in the indicator must incur a processing cost.

This cost of processing has several aspects. One is the cost of altering one's behaviour in the light of information; in the present model the agent who monitors $s$ may be expected to engage in more frequent revision of his prices and thus to incur more of the attendant costs. Another is the cost of figuring out what to do with the information. In the present model the agent who chooses (with all others) not to monitor can calculate the optimal price to post by using (15). The only information he needs to calculate this price consists of the values of $\bar{M}, k, n$, and $\beta$. But the agent who monitors and sets a relative price according to (23) must also know the values of $\gamma$ and $g_{0}$ Finally there is the simple cost of paying attention to the communication of information. Generally speaking communication is not costless either to the sender or to the receiver. In the present model agents may not want to be bothered listening to what the monetary authority has to say. 
5. A VARIANT OF THE BASIC MODEL: MONETARY POLICY AND THE EFFICIENCY OF MONITORING

One special feature of the basic model employed above is that the terms $m$ and $x$ enter into the effective demand equation (5) with the same coefficient. This is why the optimal reaction coefficient $\hat{g}$ always makes the expected level of output (conditional on s) equal to its optimal value, $\bar{q}(c f .(18))$ 。 When $m$ and $x$ have different random coefficients then Brainard's (1967) analysis suggests that the optimal value of the reaction coefficient will generally be smaller than this. Such a case is easily constructed by replacing the utility function (1) with the variant:

$$
\mathrm{U}=\mathrm{K}(\hat{\mathrm{q}}-\mathrm{x})^{\mathrm{a}} \hat{\mathrm{m}}^{1-\mathrm{a}}-(\mathrm{k} / 2) \mathrm{q}^{2}
$$

in which case the indirect utility function is still given by (4), but the effective demand function becomes:

$$
q=b m+x
$$

As in (17) and (18), the value of output with or without monitoring can be expressed as:

$$
\begin{aligned}
& q_{n}^{1}=b\left[\bar{m}_{n}-\gamma s / \beta\right]+c s \\
& q_{n}^{2}=b \bar{m}_{n}(1-g s)+c s
\end{aligned}
$$

Once again the expected value of output is:

$$
E\left(q_{n}^{1}\right)=E\left(q_{n}^{1} \mid s\right)=E\left(q_{n}^{2}\right)=\bar{q}_{n}
$$

and the variance of output is:

$$
\begin{aligned}
& \operatorname{var} q_{n}^{1}=\sigma_{b}^{2} \bar{m}_{n}^{2}+\sigma_{s}^{2}\left[\sigma_{c}^{2}+\gamma^{2} \sigma_{b}^{2} / \beta^{2}\right] \\
& \operatorname{var} q_{n}^{2}=\sigma_{b}^{2} \bar{m}_{n}^{2}+\sigma_{s}^{2}\left[\sigma_{c}^{2}+\left(\gamma-g \bar{m}_{n} \beta\right)^{2}+\left(g \bar{m}_{n}\right)^{2} \sigma_{b}^{2}\right]
\end{aligned}
$$

Let us again restrict our attention to the limiting case of perfect homogeneity. 
As before, the optimal value $g^{\prime}$ of the reaction coefficient will be the one that minimizes var $\mathrm{q}^{2}$. That is:

$$
g^{\prime}=\lambda_{b} \gamma / \ddot{q}
$$

If the Activist policy $g=g^{\prime}$ pursued and no monitoring occurs then:

$$
E\left(q^{2} \mid s\right)=\bar{q}+\left(1-\lambda_{b}\right) \gamma s
$$

As in Brainard's analysis, only the fraction $\lambda_{b}$ of the predicted effect of a change in the indicator is offset by optimal monetary policy. In contrast to this, (39) implies that all of the predicted effect will be offset by the outcome of monitoring. Thus optimal monetary policy without monitoring can in this case accomplish more than monitoring. With private monitoring the real money supply will overreact to information about aggregate disturbances. Specifically, it follows that the social gain to monitoring when $g=g^{\prime}$ is :

$$
v^{1}\left(g^{\prime}\right)-v^{2}\left(g^{\prime}\right)=(k / 2) \lambda_{c} \sigma_{x}^{2} \sigma_{b}^{2}\left[1 /\left(\beta^{2}+\sigma_{b}^{2}\right)-1 / \beta^{2}\right]<0 .
$$

Optimal monetary policy can be characterized in this variant model as we did in the basic model, with results that are similar, but with a complication because even when $g=g^{\prime}$ and the social gain to monitoring is negative, the private gain in this case is actually positive. Specifically: ${ }^{9}$

$$
v^{3}(g)-v^{2}(g)=(k / 2) \lambda_{c} \sigma_{x}^{2}\left(1-\lambda_{b} g / g^{\prime}\right)^{2}
$$

from which it follows that $\mathrm{v}^{3}\left(\mathrm{~g}^{\prime}\right)-\mathrm{v}^{2}\left(\mathrm{~g}^{\prime}\right)>0$. Thus optimal monetary policy may require $g$ to be somewhat larger than $g$ ' so that people will not be motivated to monitor.

For our purposes the important feature of optimal monetary policy is that the Activist policy $\left(g=g^{\prime}\right)$ will be optimal whenever:

$$
(k / 2) \lambda_{c} \sigma_{x}^{2}\left(1-\lambda_{b}\right)^{2} \leqq z_{p}+z_{c}<(k / 2) \lambda_{c} \sigma_{x}^{2}
$$

and 


$$
z_{a} \leqq(k / 2) \lambda_{c} \sigma_{x}^{2} \sigma_{b}^{2}\left[1 /\left(\beta^{2}+\sigma_{b}^{2}\right)-1 / \beta^{2}\right]
$$

If (46) is satisfied then monitoring will occur under a Neutral or Disseminating policy but not under an Activist policy. If (47) also holds then the Activist policy is optimal because its cost (relative to $v^{2}\left(g^{\prime}\right)$ ) is $z_{a}$, whereas, from (44), the cost of the other policies will exceed the RHS of (47) by the sum of monitoring and administrative costs.

Thus, an activist monetary polity can be justified because the monetary authority, by avoiding the overreaction to the indicator that would occur with monitoring, is able to accomplish more than could be accomplished by private monitoring. The overreaction of private agents monitoring $s$ occurs because each individual sees himself as being able to offset the effect of $s$ be changing his relative price, the coefficient of which, $n$, is known with certainty. Thus, he will try to offset completely the predicted effects of a change in s. As Brainard has shown, this is the optimal policy when the effect of the price setter's action can indeed be predicted with certainty. But the effect of every agent trying to alter his relative price is for the absolute price level to change, whose effect cannot be predicted with certainty. As Brainard has also shown the optimal reaction when the effect of policy is uncertain is to attempt to offset less than 100 percent of the predicted effect of the disturbance. The crucial assumption in this argument is that the degree of uncertainty attached to the effects of relative-price changes is different from that attached to absolute-price changes. Private agents take the former into account but not the 1atter. In the particular model used above the former uncertainty is less than the latter, but this is not essential to the argument. In the reverse case private agents would underreact to monitored aggregate disturbances, once again giving a rationale to an activist policy. 
6. CONCLUSION

In sumnary, this paper has argued that an activist monetary policy may be justified even when people's expectations are formed rationally, if there are costs of gathering and processing information and if there is uncertainty concerning the exact values of parameters in the economic system. The justification that we have presented is twofold; first, that private agents may not be motivated to use information that can be used profitably by the monetary authority, and second, that even if they are motivated to use it they may not make as good use of it as could the monetary authority.

It does not appear as if the assumption of costly price-adjustment is crucial for the above results. For the equilibrium condition that closes this model; namely that the conditional expectation of excess demand equal zero, is also the equilibrium condition in a broad class of continuous-market-clearing models in which goods are durable and risk-neutral speculators are well enough funded to dominate the market price (see Howitt (1978)). However, a precise analysis of such a model has not yet been undertaken along the above lines, and will probably be much more complicated because of the necessary added intertemporal dimension.

The paper has not addressed the question of whether or not the particular conditions derived above for the optimality of an activist policy actually exist in any real world situation. The purpose has been simply to argue that as a matter of principle the assumption of rational expectations does not imply the uselessness of an activist policy. It depends at least upon the factors discussed above. As well as these factors any balanced evaluation of alternative monetary policies should take into account at least two other important considerations. First, as Hayek (1945) has argued, the most important problem to be resolved is probably not how to vary the money 
supply but whom to entrust with this task. An activist policy will work only if the authority can be entrusted or persuaded to pursue the public interest instead of his own interest, and to pursue it competently。 Second, as Hayek has also argued, the centralization of decision-making is most easily rationalized when the decisions require the use of general knowledge rather than local, specific knowledge. In the model of the present paper every individual agent is essentially identical, so there is no clear distinction between these two kinds of knowledge. But more generally one would expect the aggregate disturbances to which monetary policy reacts to come under the heading of general knowledge, about which most individual agents can be expected to have little expertise. Thus a further argument is favour of an activist policy is that it allows society to centralize, and thus to bring to bear an efficient degree of expertise on decisions concerning such general knowledge.

Finally, it is worth noting that with stochastic parameters the assumption of rational expectations is less controversial than it may seem. In particular we are not begging the question of how the agents came to know the exact structure of the economic system when in real life we economists know so little about it. The probability distributions assumed to govern the behaviour of the random variables can be interpreted as purely subjective, bearing no necessary relationship to observed distributions. What is being assumed is simply that private agents, the monetary authority, and we the observers of their behaviour share the same probabilistic beliefs. Of course another important consideration that we have not touched upon here is the question of how these beliefs are formed. 
${ }^{1}$ See Sargent and Wallace (1975). The proposition is derived in a more general context by Barro (1976).

2This is also the message of Benjamin Friedman's (1975) paper, which shows the similarity of rational expectations to error-learning during the learning process.

${ }^{3}$ See, however, Lucas (1975) and Sargent (1976) for attempts to provide such an explanation based on rational expectations. See also Barro's (1977) attempt at empirical verification of the theory.

${ }^{4}$ This point has been stressed by Rutledge (1974), Frenkel (1975), Feige and Pearce (1976), Laidler (1978), and Shiller (1978).

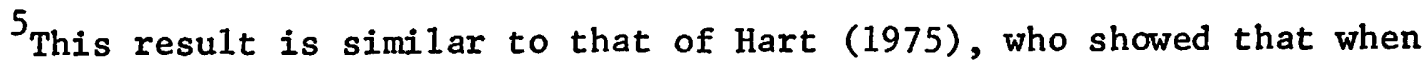
there is more than one Arrow-Debreu market missing the addition of a new market may result in an equilibrium allocation that is Pareto-inferior to the initial one.

${ }^{6}$ The expression $\phi$ denotes the empty set.

${ }^{7}$ An almost idential condition was assumed to hold by Fischer (1977, pp. 195-197) and by Phelps and Taylor (1977, pp. 166-170)。

${ }^{8}$ The limiting case of perfect homogeneity is denoted by the absence of the subscript $n$ on the variables $\bar{q}_{n}, \bar{m}_{n}, v_{n}^{1}, \hat{g}_{n}$, etc.

${ }^{9}$ See Appendix. 


\section{References}

Barro, R. J., "Rational Expectations and the Role of Monetary Policy," Journal of Monetary Economics, 2, January 1976, 1-32.

Barro, R. J., "Unanticipated Money Growth and Unemployment in the United States," American Economic Review, 67, 1977, 101-115。

Brainard, W., "Uncertainty and the Effectiveness of Policy," American Economic Association Papers and Proceedings 57, 1967, 411-425.

Feige, E. L., and Pearce, D。 Ko, "Economically Rational Expectations: Are Innovations in the Rate of Inflation Independent of Innovations in Measures of Monetary and Fiscal Policy?" Journal of Political Economy, 84, June 1976, 499-522.

Fischer, S。, "Long Term Contracts, Rational Expectations and the Optimal Money Supply Rule," Journal of Political Economy, 85, February 1977, 191-206.

Frenkel, J., "Inflation and the Formation of Expectations," Journal of Monetary Economics, 1, October 1975, 403-422.

Friedman, B。, "Rational Expectations Are Really Adaptive After A11," unpublished paper, Harvard University, 1975.

Friedman, M. "The Effects of a Full-Employment Policy on Economic Stability: A Formal Analysis," in Essays in Positive Economics, by M. Friedman, Chicago: University of Chicago Press, 1953.

Friedman, M. "The Role of Monetary Policy," American Economic Review, 58, March 1968, 1-17.

Hart, 0. "On the Optimality of Equilibrium when Markets are Incomplete," Journal of Economic Theory, 11, December 1975, 418-443.

Hayek, F. "The Use of Knowledge in Society," American Economic Review, 35, 1945, 519-530. 
Howitt, P. W. "The Role of Speculation in Competitive Price-Dynamics," Review of Economic Studies, forthcoming, 1978.

Laidler, D. E. W., "Money and Money Income: An Essay on the 'Transmission Mechanism'," Journal of Monetary Economics, 1978, forthcoming.

Lucas, R. E., "An Equilibrium Model of the Business Cycle," Journal of Political Economy, 83, December 1975, 1113-1144.

Phelps, E. S。 and Taylor, J。 B., "Stabilizing Powers of Monetary Policy under Rational Expectations," Journal of Political Economy, 85, February 1977, 163-190.

Poole, $W_{0}$, "Rational Expectations in the Macro-Model," Brookings Papers on Economic Activity, 2, 1976, 463-505。

Rutledge, J。, A Monetarist Mode1 of Inflationary Expectations, Toronto, Lexington, 1974.

Sargent, T. J., "A Classical Macroeconometric Model for the United States," Journal of Political Economy, 84, April 1976, 207-237.

, and Wallace, N., "'Rational' Expectations, the Optimal Monetary Instrument, and the Optimal Money Supply Rule," Journal of Political Economy, 83, Apri1 1975, 241-254.

Shiller, R. J. "Rational Expectations and the Dynamic Structure of Macroeconomic Mode1s: A Critical Review," Journal of Monetary Economics, 4, January 1978, 1-44.

Taylor, J. B. "Monetary Policy During a Transition to Rational Expectations," Journal of Political Economy, 83, October 1975, 1009-1021. 


\section{Appendix}

This appendix sketches a formal derivation of the private value of monitoring. In general terms, suppose that a decision-maker has an information set I and his problem is to choose the value of a decisionvariable $\mathrm{x}$ so as to:

$$
\text { (A.1) } \quad \underset{\{\mathrm{x}\}}{\operatorname{Max}} \mathrm{E}\left[\alpha_{\mathrm{o}}+\alpha_{1} \mathrm{x}+\alpha_{2} \mathrm{x}^{2} \mid \mathrm{I}\right]
$$

where the $\alpha_{i}$ 's are random parameters. Then the expected value of receiving the information contained in the new information set $I^{\prime}$ is the expected difference in the optimized value of (A.1) resulting from replacing I by I'; that is;

$$
\text { (A.2) } \quad W\left(I^{\prime}\right)-W(I)=E\left[\left(E\left(\alpha_{1} \mid I\right)\right)^{2} / 4 E\left(\alpha_{2} \mid I\right)-\left(E\left(\alpha_{1} \mid I^{\prime}\right)\right)^{2} / 4 E\left(\alpha_{2} \mid I^{\prime}\right)\right]
$$

1. To derive (24) from (A.2) note that in this case, $\alpha_{1}=\left(q_{n}^{2}+n\right)(1+n k)$, $\alpha_{2}=-(n / 2)(2+n k), I=\varnothing$ and $I^{\prime}=\{s\}$.

2. To derive (26), note that in this case, $\alpha_{1}=e_{n}\left(q_{n}^{2}+n\right)(1+n k)$, $\alpha_{2}=-e_{n}^{2}(n / 2)(2+n k), I=\phi$, and $I^{\prime}=\{s\}$ 。

3. To derive (45) proceed exactly as in deriving (24), and take the limit as $\mathfrak{n} \rightarrow \infty$. 